\title{
Vendor Consolidation for a Small Appliance Company
}

\author{
Fred C.C. Yuen, K.L. Choy, H.Y. Lam \\ Department of Industrial and Systems Engineering \\ The Hong Kong Polytechnic University \\ Hong Kong, China
}

\begin{abstract}
Vendor consolidation is becoming an important management focus in recent years due to the need to sharpen cost performance to increase competition in the fast changing business environment. Vendor consolidation can assist company to streamline its operation, concentrate buying power and reduce purchase price and transaction cost. This paper proposed an intelligent vendor consolidation support system (VCSS) by integrating Analytical Hierarchical Process (AHP), Genetic Algorithms (GA) and Artificial Neural Network (ANN) to rank vendors according to the predefined elimination criteria and the performance of individual vendors in each area of the criteria. With this ranking of vendors, the vendors with inferior performance will be isolated and eliminated to achieve the target number of vendors.
\end{abstract}

Keywords-Vendor consolidation, Supplier base reduction, AHP, GA, ANN, Mathematical modelling

\section{INTRODUCTION}

With the slowdown in world economic growth and the heighten in possibility of economic stagnation or economic depression, the Asia manufacturing industry face a hard time in the coming years. According to Hong Kong Trade Development Council, the domestic export had been increased by $3 \%$ in the Jan-July of 2015, while the total exports of household electrical appliances decreased drastically by $12 \%$ in the first half of 2015[1].

With the increase in competition and decrease in profit margin, the small appliance industry has to improve its performance and strengthen its competence in order to survive and stay in the industry. One alternative is to reduce operating cost. It is costly to maintain a massive number of vendors of which majority of them are in-active and some are of inferior performance. It is thus necessary to consolidate the existing vendors to locate and highlight the inferior vendors so that they will be isolated and eliminated and orders will only be allocated to the qualified out-perform vendors to obtain quantity discount while on the other hand meets the quality, reliability and safety requirements. It also enables the company to formulate its strategy in alliance with the outperform vendors.

The existing method to consolidate vendors is heavily relying on human judgement. Weighting is assigned to each performance factors for each vendor. The total weightings are summed up to obtain a total score for each vendor. The vendors with lowest score in the ranking hierarchy are them identified and isolated. This method induces risks in the consolidation process due to the subjective human judgement and interpretation.
To increase accuracy of the vendor consolidation process and to quantify the result to provide information to assist senior management of the small appliance industry to make final judgement on the isolation and elimination list of vendor, it is proposed to develop and formulate an intelligent vendor consolidation support system (VCSS) to be incorporated into the decision support system of the company to facilitate management decision in vendor consolidation.

This paper is divided into 6 sections. Section 2 contains a literature study that includes a review of vendor base reduction and application of AHP, GA and ANN in ranking of vendors. This is followed by the approach of study and framework of methodology for the proposed VCSS in section 3. Section 4 is a case study conducted on the proposed system. Section 5 presents the results and compares the feasibility of the proposed method with the existing manual method. Section 6 presents the conclusion of this paper and future research direction.

\section{LITERATURE REVIEW}

Vendor consolidation is a continuous process that involves reducing the supplier base so as to achieve economies of scale to lower prices and freight charges, improving quality and strengthening supply agreements. According to Sarkar and Mohapatra [2], the concept of supplier base reduction refers to the downsizing of the number of existing suppliers within the supplier base. Sollish \& Semanik [3] stated that company needs to identify criteria to determine which vendors should be targeted for elimination. Sarkar and Mohapatra [2] pointed out performance, as an important criterion when selecting suppliers for elimination and Ogden \& Carter [4] mentioned that a systematic elimination of inferior vendors can be based on poor cost performance, quality, delivery performance etc. After the elimination criteria had been determined, it will be necessary to rank the vendor based on the elimination criteria. There are qualitative and quantitative means to evaluate and rank the vendor based on the elimination criteria. This paper will focus on the adaptation of Analytical Hierarchical Process (AHP), Genetic Algorithms (GA) and Artificial Neural Network (ANN) to rank the vendors based on the elimination criteria.

AHP is a popular and elementary multi-criteria decision making method. This method helps choose the best from numerous alternatives which are assessed regarding a few criteria. Nydick and Hill [5], Barbarosoglu and Yazgac [6] propose the use of AHP to deal with imprecision in supplier ranking. AHP rank the vendor based on the relative importance of one criterion versus another criterion and also 
the relative preference for one supplier versus the other on a criterion.

The GA is a global search procedure that searches from one population of solutions to another, focusing on the area of the best solution so far, while continuously sampling the total parameter space. GA is a search and optimization algorithm that derive their computational mechanisms from natural selection and natural adaption. GA is widely used because it can solve multi-dimensional, non-differential, non-continuous, and even non-parametrical problems. Arsovski et al. [11] used GA to solve supplier selection problem. Rungreunganaun and Woarawhichai [12] applied GA for inventory lot sizing problem with suppler selection.

ANN had been developed by Larson G.B. [7] and Quin L. [8]. ANN based algorithms are claimed to be helpful for practical industrial applications especially for dynamic situations. The network is defined by the neurons and their connections and weights. All neurons are organized into layers and the layers define the order in which the activations are computed. Supplier selection using ANN alone is represented in Jinlong et al. [9]. An analysis on various activation functions of ANN was represented by Jones et al. [10]. Sigmoid activation function was found to give minimum error for the number of epochs.

A hybrid method using AHP and ANN for supplier selection was provided by Ariffin et al. [13], Kumar and Roy [14] and Lakshmanpriya et al. [15], where AHP is used to determine the weights of criteria, and the ANN to select the supplier. Other approach on applications of GA to ANN involves optimization of the NN using GA for the weights computation. To summarize, the review of the above literature shows that it is essential to have an intelligent system integrating AHP, GA and ANN for achieving an accurate result for vendor consolidation by incorporating the strengths of each method.

\section{APPROACH OF THE STUDY}

In the proposed intelligent vendor consolidation support system (VCSS), the evaluation criteria for vendor isolation and elimination will first be established. AHP will be adopted for pairwise comparison to calculate the weight of each elimination criterion identified for vendor consolidation, and consistency test will be conducted with AHP. The integrate weights from AHP will be fed to GA for fitness evaluation and to optimize the weights. The optimum weights from GA will be input to ANN together with the weights of criteria and weights of supplier generated from AHP. ANN will then be utilized to generate the final output i.e. the final score of the vendor for location and isolation of inferior performance vendor. Finally, the output from the intelligent VCSS will be evaluated to see if it fits the company's requirements and environment. This can be done by comparing the output result on vendor scoring with the company's manual system on vendor ranking. The similarities and differences will then be cross-referenced and benchmarked with the managers' final decision.
The proposed framework of methodology for the intelligent vendor consolidation support system (VCSS) is depicted in Fig. 1.

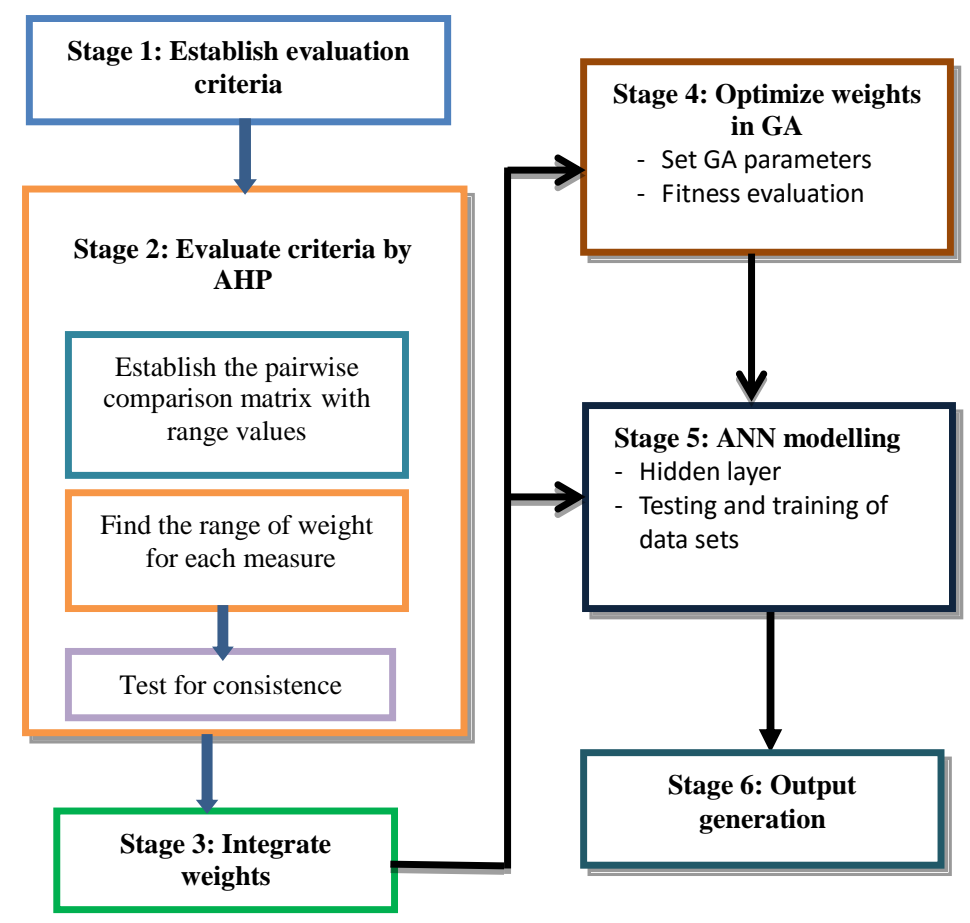

Fig. 1. Framework of methodology for VCSS

\section{CASE STUdY}

This section covers (i) company background, (ii) ranking of vendors for elimination of inferior performance vendors.

\section{A. Company background}

$\mathrm{XYZ}$ is a Hong Kong based family own small appliance company. It has 4 factories in South China employing around 20,000 workers. Like typical manufacturing companies in South China, it is highly vertical integrated to produce finished products with manufacturing capabilities of plastic injection molding, electronic assembly of PCBA, die-casting, metal stamping, painting and final assembly. The supplier base includes raw materials of metal, plastic resins, electronic components, packaging items, chemicals and electromechanical items.

\section{B. Existing vendor performance}

Table 1 depicts the vendor performance data from the small appliance company on the supply of electronic components from 5 current vendors. 
TABLE 1 VENDOR PERFORMANCE

\begin{tabular}{|c|c|c|c|c|c|}
\hline $\begin{array}{c}\text { Vendor } \\
\text { code }\end{array}$ & $\begin{array}{c}\text { Quality } \\
(\% \\
\text { defect) }\end{array}$ & $\begin{array}{c}\text { Cost (\% } \\
\text { increase) }\end{array}$ & $\begin{array}{c}\text { Service } \\
(\text { response } \\
\text { time) }\end{array}$ & $\begin{array}{c}\text { Technical } \\
\text { Capability }\end{array}$ & $\begin{array}{c}\text { Delivery } \\
\text { (days) }\end{array}$ \\
\hline $\max 0.009 \%$ & $\max 5 \%$ & $\max 24$ hrs & $\max 9$ & $\max$ 8 days \\
\hline 1 & 0.005 & 2.0 & 5 & 7 & 3 \\
\hline 2 & 0.002 & 1.5 & 13 & 7 & 5 \\
\hline 3 & 0.004 & 3.5 & 20 & 6 & 5 \\
\hline 4 & 0.008 & 3.5 & 5 & 3 & 2 \\
\hline 5 & 0.001 & 4.5 & 8 & 4 & 8 \\
\hline
\end{tabular}

Quality is in terms of percentage defect and the maximum limit is $0.009 \%$. Cost is the percentage increase compared with the past purchase, the smaller the better and it is preferred to have cost reduction, i.e. negative cost increase. Service is in terms of response time from supplier and the preferred response time is within 24 hours. Technical capability is a valuable asset and supplier with higher technical competence is more preferable. Delivery is in terms of days and minimum deviation from the required delivery date of the goods is preferred.

\section{AHP Pairwise Comparison}

Table 2 shows the relative importance of each of the elimination criteria, i.e. quality, cost, service, technical capacity and delivery for the small appliance company.

TABLE 2 RELATIVE IMPORTANCE OF PERFORMANCE CRITERIA

\begin{tabular}{|c|c|c|c|c|c|}
\hline Cost & Delivery & Quality & Service & $\begin{array}{c}\text { Technical } \\
\text { capability }\end{array}$ & $\begin{array}{c}\text { Total } \\
\text { Score }\end{array}$ \\
\hline $25 \%$ & $15 \%$ & $40 \%$ & $20 \%$ & $20 \%$ & $\mathbf{1 2 0 \%}$ \\
\hline
\end{tabular}

Based on this, a pairwise comparison of elimination criteria based on the AHP method is conducted and results are shown in Table 3.

TABLE 3 PAIRWISE COMPARISONS OF CRITERIA

\begin{tabular}{|c|r|r|r|r|c|}
\hline & Quality & \multicolumn{1}{c|}{ Cost } & Service & Technical & Delivery \\
\hline Quality & 1 & 4 & 5 & 5 & 9 \\
\hline Cost & $1 / 4$ & 1 & 3 & 3 & 5 \\
\hline Service & $1 / 5$ & $1 / 3$ & 1 & 1 & 3 \\
\hline Technical & $1 / 5$ & $1 / 3$ & 1 & 1 & 3 \\
\hline Delivery & $1 / 9$ & $1 / 5$ & 1 & $1 /$ & 1 \\
\hline Total & $1137 / 180$ & $513 / 15$ & 11 & $101 /$ & 21 \\
\hline
\end{tabular}

Random consistency index $(\mathrm{RI})=1.12$. By using MATLAB to calculate the Consistency ratio (CR) Consistency ratio $(\mathrm{CR})$ is found to be 0.0979 which is smaller than 0.1 and is determined as acceptable result. Subsequently, the weights of criteria can then be determined by the AHP method and the results depicted in Table 4.

\section{TABLE 4 WEIGHTS OF CRITERIA}

\begin{tabular}{|c|c|c|c|c|c|c|}
\hline & Quality & Cost & Service & Technical & Delivery & A verage \\
\hline Quality & 0.5678 & 0.6818 & 0.4545 & 0.4839 & 0.4286 & 0.5233 \\
\hline Cost & 0.1420 & 0.1705 & 0.2727 & 0.2903 & 0.2381 & 0.2227 \\
\hline Service & 0.1136 & 0.0568 & 0.0909 & 0.0968 & 0.1429 & 0.1002 \\
\hline Technical & 0.1136 & 0.0568 & 0.0909 & 0.0968 & 0.1429 & 0.1002 \\
\hline Delivery & 0.0631 & 0.0341 & 0.0909 & 0.0323 & 0.0476 & 0.0536 \\
\hline
\end{tabular}

The average weights are input weights U1 (Quality), U2 (Cost), U3 (Service), U4 (Technical) and U5 (Delivery) for the input layer of the ANN. From Table 1, the following constraints are set for the elimination criteria:

- $\quad$ Maximum allowable percentage defect is $0.009 \%$

- Maximum cost increase is within 5\%

- $\quad$ Maximum service response time is $24 \mathrm{hrs}$.

- Maximum deviation from delivery date is 8 days

Table 5 shows the scale of quality, cost, service, technical and delivery according to these constraints based on measure scale by Saaty [16].

TABLE 5 SCALES FOR THE CONSTRAINTS

\begin{tabular}{|c|c|c|c|c|c|}
\hline Scale & $\begin{array}{c}\text { Quality (\% } \\
\text { defect) }\end{array}$ & $\begin{array}{c}\text { Cost (\% } \\
\text { increase) }\end{array}$ & $\begin{array}{c}\text { Service response } \\
\text { tim e (hr) }\end{array}$ & Technical & $\begin{array}{c}\text { Delivery } \\
\text { (day) }\end{array}$ \\
\hline 1 & $0-0.001$ & $0.00-0.55$ & $0.00-2.50$ & 1 & 0 \\
\hline 2 & $0.0011-0.0020$ & $0.56-1.10$ & $2.51-5.00$ & 2 & 1 \\
\hline 3 & $0.0021-0.0030$ & $1.11-1.65$ & $7.51-10.00$ & 3 & 2 \\
\hline 4 & $0.0031-0.0040$ & $1.66-2.20$ & $10.01-12.50$ & 4 & 3 \\
\hline 5 & $0.0041-0.0050$ & $2.21-2.75$ & $12.51-15.00$ & 5 & 4 \\
\hline 6 & $0.0051-0.0060$ & $2.76-3.30$ & $15.01-17.50$ & 6 & 5 \\
\hline 7 & $0.0061-0.0070$ & $3.31-3.85$ & $17.51-20.00$ & 7 & 6 \\
\hline 8 & $0.0071-0.0080$ & $3.86-4.40$ & $20.01-22.50$ & 8 & 7 \\
\hline 9 & $0.0081-0.0090$ & $4.41-5.00$ & $22.51-24.00$ & 9 & 8 \\
\hline
\end{tabular}

Weights (Wi) of the output layer are obtained from the relative comparison of suppliers for each criterion, based on vendor performance in Table 1 and rating scale in Table 5. By repeating the steps for Table 3 and Table 4 using AHP and Consistency Ratio calculation by MATLAB, the results are depicted in Table $6-10$.

TABLE 6 RELATIVE MATRIX OF VENDORS WITH RESPECT TO QUALITY $($ CONSISTENCY RATIO $=0.0294)$

\begin{tabular}{|c|c|c|c|c|c|c|}
\hline & v1 & v2 & v3 & v4 & v5 \\
\hline v1 & 1 & $1 / 3$ & 1 & 5 & $1 / 3$ \\
\hline v2 & 3 & 1 & 2 & 7 & 1 \\
\hline v3 & 1 & $1 / 2$ & 1 & 6 & 1 \\
\hline v4 & $1 / 5$ & $1 / 7$ & \multicolumn{2}{|c|}{$1 / 6$} & 1 & $1 / 8$ \\
\hline v5 & 3 & 1 & 1 & 8 & 1 \\
\hline Tot & $81 / 5$ & $241 / 42$ & 5 & $1 / 6$ & 27 & $311 / 24$ \\
\hline
\end{tabular}
\begin{tabular}{|c|c|c|c|c|c|c|}
\hline v1 & v3 & v4 & v5 & A verage \\
\hline v1 & 0.1220 & 0.1120 & 0.1935 & 0.1852 & 0.0964 & 0.1418 \\
\hline v2 & 0.3659 & 0.3360 & 0.3871 & 0.2593 & 0.2892 & 0.3275 \\
\hline v3 & 0.1220 & 0.1680 & 0.1935 & 0.2222 & 0.2892 & 0.1990 \\
\hline v4 & 0.0244 & 0.0480 & 0.0323 & 0.0370 & 0.0361 & 0.0356 \\
\hline v5 & 0.3659 & 0.3360 & 0.1935 & 0.2963 & 0.2892 & 0.2962 \\
\hline
\end{tabular}

TABLE 7 RELATIVE MATRIX OF VENDORS WITH RESPECT TO COST (CONSISTENCY RATIO $=0.0287)$

\begin{tabular}{|c|c|c|c|c|c|c|c|c|}
\hline & v1 & \multicolumn{2}{|c|}{ v2 } & \multicolumn{2}{|c|}{ v3 } & \multicolumn{2}{|r|}{$\mathrm{v} 4$} & v5 \\
\hline v1 & 1 & \multicolumn{2}{|c|}{$1 / 2$} & \multicolumn{2}{|c|}{3} & \multicolumn{2}{|c|}{3} & 9 \\
\hline $\mathrm{v} 2$ & 2 & \multicolumn{2}{|c|}{1} & \multicolumn{2}{|c|}{4} & \multicolumn{2}{|c|}{4} & \multirow{2}{*}{10} \\
\hline v3 & $1 B$ & \multicolumn{2}{|c|}{$1 / 4$} & \multicolumn{2}{|l|}{1} & \multicolumn{2}{|c|}{1} & \\
\hline $\mathrm{v} 4$ & $1 B$ & \multicolumn{2}{|c|}{$1 / 4$} & \multicolumn{2}{|c|}{1} & \multicolumn{2}{|c|}{1} & 6 \\
\hline v5 & $1 / 9$ & \multicolumn{2}{|c|}{$1 / 10$} & \multicolumn{2}{|c|}{$1 / 6$} & \multicolumn{2}{|c|}{$1 / 6$} & 1 \\
\hline Tot & 3719 & \multicolumn{2}{|c|}{$21 / 10$} & \multicolumn{2}{|c|}{$91 / 6$} & \multicolumn{2}{|c|}{$91 / 6$} & 32 \\
\hline & v1 & $\mathrm{v} 2$ & & & & & v5 & A verage \\
\hline v1 & 0.2647 & 0.2381 & & & & & 0.2813 & 0.2877 \\
\hline $\mathrm{v} 2$ & 0.5294 & 0.4762 & & & & & 0.3125 & 0.4382 \\
\hline v3 & 0.0882 & 0.1190 & & & & & 0.1875 & 0.1226 \\
\hline $\mathrm{v} 4$ & 0.0882 & 0.1190 & & & & & 0.1875 & 0.1226 \\
\hline v5 & 0.0294 & 0.0476 & & & & & 0.0313 & 0.0289 \\
\hline
\end{tabular}


TABLE 8 RELATIVE MATRIX OF VENDORS WITH RESPECT TO SERVICE (CONSISTENCY RATIO $=0.0293$ )

\begin{tabular}{|c|c|c|c|c|c|}
\hline & v1 & v2 & v3 & v4 & v5 \\
\hline v1 & 1 & 4 & 8 & 1 & 2 \\
\hline v2 & $1 / 4$ & 1 & 5 & $1 / 4$ & $1 / 3$ \\
\hline v3 & $1 / 8$ & $1 / 5$ & 1 & $1 / 8$ & $1 / 7$ \\
\hline v4 & 1 & 4 & 8 & 1 & 2 \\
\hline v5 & $1 / 2$ & 3 & 7 & $1 / 2$ & 1 \\
\hline Tot & $27 / 8$ & $121 / 5$ & 29 & $27 / 8$ & $510 / 21$ \\
\hline
\end{tabular}

\begin{tabular}{|c|c|c|c|c|c|c|}
\hline & v1 & v2 & v3 & v4 & v5 & A verage \\
\hline v1 & 0.3478 & 0.3279 & 0.2759 & 0.3478 & 0.3652 & 0.3329 \\
\hline v2 & 0.0870 & 0.0820 & 0.1724 & 0.0870 & 0.0609 & 0.0978 \\
\hline v3 & 0.0435 & 0.0164 & 0.0345 & 0.0435 & 0.0261 & 0.0328 \\
\hline v4 & 0.3478 & 0.3279 & 0.2759 & 0.3478 & 0.3652 & 0.3329 \\
\hline v5 & 0.1739 & 0.2459 & 0.2414 & 0.1739 & 0.1826 & 0.2035 \\
\hline
\end{tabular}

TABLE 9 RELATIVE MATRIX OF VENDORS WITH RESPECT TO TECHNICAL $($ CONSISTENCY RATIO $=0.0627)$

\begin{tabular}{|c|c|c|c|c|c|}
\hline & v1 & v2 & v3 & v4 & v5 \\
\hline v1 & 1 & 1 & 2 & 4 & 3 \\
\hline v2 & 1 & 1 & 2 & 4 & 3 \\
\hline v3 & $1 / 2$ & $1 / 2$ & 1 & 3 & 2 \\
\hline v4 & $1 / 4$ & $1 / 4$ & $1 / 3$ & 1 & $1 / 2$ \\
\hline v5 & $1 / 3$ & $1 / 3$ & $1 / 2$ & 2 & 1 \\
\hline Tot & $31 / 12$ & $31 / 12$ & $55 / 6$ & 14 & $91 / 2$ \\
\hline
\end{tabular}

\begin{tabular}{|c|c|c|c|c|c|c|}
\hline & v1 & v2 & v3 & v4 & v5 & A verage \\
\hline v1 & 0.3243 & 0.3243 & 0.3429 & 0.2857 & 0.3158 & 0.3186 \\
\hline v2 & 0.3243 & 0.3243 & 0.3429 & 0.2857 & 0.3158 & 0.3186 \\
\hline v3 & 0.1622 & 0.1622 & 0.1714 & 0.2143 & 0.2105 & 0.1841 \\
\hline v4 & 0.0811 & 0.0811 & 0.0571 & 0.0714 & 0.0526 & 0.0687 \\
\hline v5 & 0.1081 & 0.1081 & 0.0857 & 0.1429 & 0.1053 & 0.1100 \\
\hline
\end{tabular}

TABLE 10 RELATIVE MATRIX OF VENDORS WITH RESPECT TO DELIVERY (CONSISTENCY RATIO $=0.0125)$

\begin{tabular}{|c|c|c|c|c|c|}
\hline & v1 & v2 & v3 & v4 & v5 \\
\hline v1 & 1 & 3 & 3 & $1 / 2$ & 7 \\
\hline v2 & $1 / 3$ & 1 & 1 & $1 / 4$ & 4 \\
\hline v3 & $1 / 3$ & 1 & 1 & $1 / 4$ & 4 \\
\hline v4 & 2 & 4 & 4 & 1 & 8 \\
\hline v5 & $1 / 7$ & $1 / 4$ & $1 / 4$ & $1 / 8$ & 1 \\
\hline Tot & $317 / 21$ & $91 / 4$ & $91 / 4$ & $21 / 8$ & 24 \\
\hline
\end{tabular}

\begin{tabular}{|c|c|c|c|c|c|c|}
\hline & v1 & v2 & v3 & v4 & v5 & A verage \\
\hline v1 & 0.2625 & 0.3243 & 0.3243 & 0.2353 & 0.2917 & 0.2876 \\
\hline v2 & 0.0875 & 0.1081 & 0.1081 & 0.1176 & 0.1667 & 0.1176 \\
\hline v3 & 0.0875 & 0.1081 & 0.1081 & 0.1176 & 0.1667 & 0.1176 \\
\hline v4 & 0.5250 & 0.4324 & 0.4324 & 0.4706 & 0.3333 & 0.4388 \\
\hline v5 & 0.0375 & 0.0270 & 0.0270 & 0.0588 & 0.0417 & 0.0384 \\
\hline
\end{tabular}

All the average values obtained from the above calculations are summarized in the final weight matrix table as shown in Table 11.

TABLE 11 WEIGHT MATRIX OF SUPPLIERS WITH RESPECT TO ALL CRITERIA

\begin{tabular}{|c|c|c|c|c|c|}
\hline & Quality & Cost & Service & Technical & Delivery \\
\hline v1 & 0.1418 & 0.2877 & 0.3329 & 0.3186 & 0.2876 \\
\hline v2 & 0.3275 & 0.4382 & 0.0978 & 0.3186 & 0.1176 \\
\hline v3 & 0.1990 & 0.1226 & 0.0328 & 0.1841 & 0.1176 \\
\hline v4 & 0.0356 & 0.1226 & 0.3329 & 0.0687 & 0.4388 \\
\hline v5 & 0.2962 & 0.0289 & 0.2035 & 0.1100 & 0.0384 \\
\hline
\end{tabular}

\section{Optimization of elimination criteria by $G A$}

The company target to minimize \% defect, cost, service response time, delivery and maximize technical competence, the vendors with inferior performance in these areas areisolated. This will be the base for formulation of the lower bound and upper bound for the linear objective function of the form $\Sigma \mathrm{WiXi}$ for each criterion to be input to MATLAB GA Toolbox. The equations are as follows:

a. Function of quality

Minimize $\mathrm{F}(\mathrm{Q})=\Sigma \mathrm{WiQi}=0.1418 \mathrm{Q} 1+0.3275 \mathrm{Q} 2+$ $0.1990 \mathrm{Q} 3+0.0356 \mathrm{Q} 4+0.2962 \mathrm{Q}$,

$0 \leq \mathrm{Q} 1, \mathrm{Q} 2, \mathrm{Q} 3, \mathrm{Q} 4, \mathrm{Q} 5 \leq 0.009$

b. Function of cost

Minimize $\mathrm{F}(\mathrm{C})=\Sigma \mathrm{WiCi}=0.2877 \mathrm{C} 1+0.4382 \mathrm{C} 2+$ $0.1226 \mathrm{CQ} 3+0.1226 \mathrm{C} 4+0.0289 \mathrm{C} 5$, $\mathrm{C} 1, \mathrm{C} 2, \mathrm{C} 3, \mathrm{C} 4, \mathrm{C} 5 \leq 5$

c. Function of Service

Minimize $\mathrm{F}(\mathrm{S})=\Sigma \mathrm{WiSi}=0.3229 \mathrm{~S} 1+0.0978 \mathrm{~S} 2+$

$0.0328 \mathrm{~S} 3+0.3329 \mathrm{~S} 4+0.2035 \mathrm{~S} 5$

$0<\mathrm{S} 1, \mathrm{~S} 2, \mathrm{~S} 3, \mathrm{~S} 4, \mathrm{~S} 5 \leq 24$

d. Function of Technical

Maximize $\mathrm{F}(\mathrm{T})=\Sigma \mathrm{WiTi}=0.3186 \mathrm{~T} 1+0.3186 \mathrm{~T} 2+$

$0.1841 \mathrm{~T} 3+0.0687 \mathrm{~T} 4+0.1100 \mathrm{~T} 5$

$1 \leq \mathrm{T} 1, \mathrm{~T} 2, \mathrm{~T} 3, \mathrm{~T} 4, \mathrm{~T} 5 \leq 9$

e. Function of Delivery

Minimize $\mathrm{F}(\mathrm{D})=\Sigma \mathrm{WiDi}=0.2876 \mathrm{D} 1+0.1176 \mathrm{D} 2+$

$0.1176 \mathrm{D} 3+0.4388 \mathrm{D} 4+0.0384 \mathrm{D} 5$

$0 \leq \mathrm{D} 1, \mathrm{D} 2, \mathrm{D} 3, \mathrm{D} 4, \mathrm{D} 5 \leq 8$

The above equations are optimized using GA Toolbox in MATLAB software, using the following parameter settings:

Population size $=25$

Population type $=$ Double vector

Scaling function $=$ rank

Selection $=$ roulette wheel

Crossover fraction $=0.8$

Crossover function $=$ scattered

Mutation $=$ adaptive feasible

Hybrid function $=$ none

Stopping criteria $=50$

The GA function in MATLAB assumes the fitness function will take one input $\mathrm{X}$ where $\mathrm{X}$ has as many elements as number of variables in the problem. The fitness function computes the value of the function and returns that scalar value in its one return argument $F(X)$.

Table 12 shows the optimum function value of each of the criteria obtained from GA Toolbox in MATLAB and these optimum function values are used as an input to the input layer of the ANN decision making model 
TABLE 12 OPTIMUM VALUES OF CRITERIA

\begin{tabular}{|c|c|}
\hline Criteria & Optimum Value \\
\hline Function of Quality & -9.97 \\
\hline Function of Cost & -12.11 \\
\hline Function of Service & -5.8935 \\
\hline Function of Technical & 9.8 \\
\hline Function of Delivery & -12.05 \\
\hline
\end{tabular}

E. Determination of Final Score by ANN

Assumptions

a. Single layer feed forward neural network

b. SIGMODIAL function

c. $\quad$ Yci $=1 /\left(1+\mathrm{e}^{-\alpha \mathrm{I}}\right), \mathrm{I}=(\Sigma \mathrm{XiWci}+\mathrm{Bias}), \mathrm{Wci}=$ weigh of criteria, $\mathrm{Xi}=$ input value for input layer, $\mathrm{Yci}=$ output value for hidden layer

d. $Y v i=1 /\left(1+e^{-\alpha p}\right), P=(\Sigma Y c i W v i+$ Bias $)$, Wvi = weigh of criteria for vendor, Yvi $=$ Total score of vendor

e. $\alpha=$ slope parameter $=1$

f. $\quad$ Bias $=0.3$

\section{1) Input Layer Calculation}

Let the optimum value in Table 12 be the input $\mathrm{Xi}$ and use the average of weights in Table 4 to be the weigh $\mathrm{Wi}$, the output of the input layer can be derived, as shown in Table 13. For example, $\Sigma$ XiWci + Bias $=-9.97 \times 0.5233+(-$ $9.97 \times 0.22271)+(-9.97 \times 0.10018)+(-9.97 \times 0.10018)+(-$ $9.97 \times 0.05359)+0.3=-9.67$.

\section{TABLE 13 INPUT LAYER CALCULATION}

\begin{tabular}{|c|c|c|c|c|}
\hline input X i & w eight W i & bias & $\begin{array}{c}\text { sum X iW ci } \\
+ \text { bias }\end{array}$ & Y ci \\
\hline-9.97 & 0.52333 & 0.3 & -9.67 & $6.31459 \mathrm{E}-05$ \\
\hline-12.11 & 0.22271 & 0.3 & -11.81 & $7.42983 \mathrm{E}-06$ \\
\hline-5.8935 & 0.10018 & 0.3 & -5.5935 & 0.003708176 \\
\hline 9.8 & 0.10018 & 0.3 & 10.1 & 0.999958922 \\
\hline-12.05 & 0.05359 & 0.3 & -11.75 & $7.88926 \mathrm{E}-06$ \\
\hline
\end{tabular}

\section{2) Output Layer Calculation}

Using the same formula, let Yi from Table 13 to be the input to the output of final score, and use values from Table 11 as the weighs, the output layer for the final score is calculated, as shown in Table 14. For example, $\Sigma$ YciWvi + Bias $=6.31459 \mathrm{E}-05 \times 0.141814067+7.42983 \mathrm{E}-06 \mathrm{x}$ $0.287719315+0.003708 \times 0.3329201+0.99995892 \times$ $0.31860191+7.889 \mathrm{E}-06 \times 0.287621887+0.3=0.650181$

\section{TABLE 14 OUTPUT LAYER CALCULATIONS FOR THE FINAL SCORE}

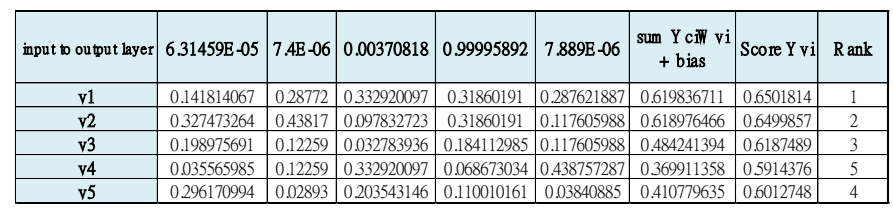

Based on the final score, vendor 4 and vendor 5 should be isolated and eliminated.

\section{RESUlTS AND DiscUSSION}

Based on the past record on manual weighing assignment and judgement system currently utilized by the company, Table 15 depicted the current ranking of the suppliers adopted by the company.

TABLE 15 RESULT OF MANUAL RANKING SYSTEM

\begin{tabular}{|c|c|c|c|c|c|c|c|}
\hline \multirow{2}{*}{$\begin{array}{c}\text { Vendor } \\
\text { code }\end{array}$} & Cost & Delivery & Quality & Service & $\begin{array}{c}\text { Technical } \\
\text { Capability }\end{array}$ & $\begin{array}{c}\text { Total } \\
\text { Score } \\
\mathbf{1 2 0} \%\end{array}$ & $\begin{array}{c}\text { Supplier } \\
\text { Selection } \\
\text { Priority }\end{array}$ \\
\cline { 2 - 8 } & $25 \%$ & $15 \%$ & $40 \%$ & $20 \%$ & $20 \%$ & & \\
\hline 1 & 19 & 12 & 35 & 19 & 14.9 & $\mathbf{1 0 0}$ & $\mathbf{1}$ \\
\hline 2 & 20 & 10 & 38 & 16 & 14.8 & $\mathbf{9 9}$ & $\mathbf{2}$ \\
\hline 3 & 16 & 10 & 36 & 12 & 14.1 & $\mathbf{8 8}$ & $\mathbf{4}$ \\
\hline 4 & 16 & 13 & 29 & 19 & 12.6 & $\mathbf{9 0}$ & $\mathbf{3}$ \\
\hline 5 & 10 & 8 & 39 & 18 & 13.3 & $\mathbf{8 8}$ & $\mathbf{4}$ \\
\hline
\end{tabular}

Compared result of Table 14 with Table 15, it can be seem that for the manual system, vendor 3 and 5 should be isolated while for the mathematical model revealed that vendor 4 and 5 should be isolated and eliminated. The supplier ranking based on AHP alone can be calculated and is shown in Table 16.

TABLE 16 RESULT OF AHP RANKING

\begin{tabular}{|c|c|c|c|c|c|c|c|}
\hline & Q uality & Cost & Service & Technical & Delivery & Total & Rank \\
\hline v1 & 0.1418 & 0.2877 & 0.3329 & 0.3186 & 0.2876 & 1.3687 & 1 \\
\hline v2 & 0.3275 & 0.4382 & 0.0978 & 0.3186 & 0.1176 & 1.2997 & 2 \\
\hline v3 & 0.1990 & 0.1226 & 0.0328 & 0.1841 & 0.1176 & 0.6561 & 5 \\
\hline v4 & 0.0356 & 0.1226 & 0.3329 & 0.0687 & 0.4388 & 0.9985 & 3 \\
\hline v5 & 0.2962 & 0.0289 & 0.2035 & 0.1100 & 0.0384 & 0.6771 & 4 \\
\hline
\end{tabular}

Subsequently, the comparison of manual ranking, AHP ranking and intelligent model ranking is shown in Table 17.

TABLE 17 RESULTS OF DIFFERENT METHODS

\begin{tabular}{|c|c|c|c|}
\hline & Manual System & AHP & AHP+GA+ANN \\
\hline v1 & 1 & 1 & 1 \\
\hline v2 & 2 & 2 & 2 \\
\hline v3 & $\mathbf{4}$ & $\mathbf{5}$ & $\mathbf{3}$ \\
\hline v4 & $\mathbf{3}$ & $\mathbf{3}$ & $\mathbf{5}$ \\
\hline v5 & $\mathbf{4}$ & $\mathbf{4}$ & $\mathbf{4}$ \\
\hline
\end{tabular}

The reason for the deviation is due to the fact that vendor 4 scores very high marks on delivery and service which contributes to the higher total marks for vendor 4 compared to vendor 3 and 5, even though vendor 4 scores the lowest mark on quality (as shown in Table 18). Since quality is a very important aspect and carries highest weights, taken this into account, it should affect the final weight of vendor 4 and thus vendor 4 should have a lower ranking when compared to vendor 3 and 5 . Hence the result of $A H P+G A+A N N$ can reflect this hidden aspect which the manual system and AHP alone cannot take this into account.

TABLE 18 PERFORMANCE OF VENDORS

\begin{tabular}{|c|c|c|c|c|c|}
\hline \multirow{2}{*}{$\begin{array}{c}\text { Vendor } \\
\text { Code }\end{array}$} & Cost & Delivery & Quality & Service & $\begin{array}{c}\text { Technical } \\
\text { capability }\end{array}$ \\
\cline { 2 - 6 } & $25 \%$ & $15 \%$ & $40 \%$ & $20 \%$ & $20 \%$ \\
\hline 1 & 19 & 12 & 35 & 19 & 14.9 \\
\hline 2 & 20 & 10 & 38 & 16 & 14.8 \\
\hline 3 & 16 & 10 & 36 & 12 & 14.1 \\
\hline 4 & 16 & 13 & 29 & 19 & 12.6 \\
\hline 5 & 10 & 8 & 39 & 18 & 13.3 \\
\hline
\end{tabular}




\section{CONCLUSION}

The model derived provide result better than the result obtained from the existing manual system of the company and thus can be incorporated in the decision support system of the company to provide valuable information to the senior management for timely and efficiently decision making on vendor consolidation. With the proposed VCSS, manual efforts and judgements involved in calculation and identification of the inferior vendor for isolation and elimination will inevitable be minimize and more accurate results can be obtained. Intensify training of model will further fine tune the result. Further analysis should be conducted on single model such as run on GA alone and ANN alone to exam if same result will be achieved using different model and algorithm and also to determine which method is the best. Sensitivity analysis should also be conducted to see how a minor change in each of the criteria will affect the overall result. With this, it will be able to push the suppliers to improve their performance in order to be more competitive than its competitors. The criteria for vendor elimination should also be further breakdown to include more details for comparison. For example, the measure of defect on quality aspect can be further breakdown into incoming quality defect, in-line defect, and after sales defect reported by after sales service. Different weighing can be assigned to defect percentage in each stage which have different impact and consequences to the operation, the image and the profit of the company.

\section{ACKNOWLEDGMENT}

The author would like to thank the Research Office of the Hong Kong Polytechnic University for supporting the project (Project Code: G-UA7Z).

\section{REFERENCES}

[1] W. Chu, "Household Electrical Appliances Industry in Hong Kong" Hong Kong Trade Development Council, Aug 2015
[2] A. Sarkar and P.K. Mohapatra, "Evalutaion of supplier capability and performance: A method for supply base reduction" Journal of Purchasing \& Supply Management, Issue 12, pp. 148-163., 2006

[3] F. Sollish, J. Semanik, "Strategic Global Sourcing Best Practices" 1 ed. New Jersey: Hoboken, 2011.

[4] J.A. Ogden, P.L. Carter, "The supply base reduction process: an empirical investigation" The International Journal of Logistics Management, 19(2008), pp. 5-28, 2008.

[5] Nydick, R.L. Hill, "Using the Analytic Hierarchy Process to structure the supplier selection procedure" International Journal of Purchasing and Material Management 28 (2), pp. 31-36, 1992

[6] G. Barbarosoglu, T. Yazgac, "An application of the analytic hierarchy process to the supplier selection problem" Production and Inventory Management Journal, pp. 14-21, 1997

[7] G.B. Larson, "An ANN pruning algorithm based approach to vendor selection" Journal of Systems Management (USA), vol. 46, no. 5, pp. 56-60, 1995

[8] L. Quin, "An ANN pruning algorithm based approach to vendor selection", Kybernetes, vol. 38, 3-4, pp. 314-320, 2009

[9] Z. Jinlong, W. Siying and L. Zhicheng, "A supplier selecting system using neural network" IEE International Conference on Intelligent Processing System, Beijing, China, pp. 468-471, 1997

[10] S.A. Jones, P. Sibi, and P. Siddarth, "Analysis of different activation functions using back propagation neural networks" Journal of Theoretical and Applied Information Technology, Vol. 47, No. 3, pp.1264-1268, 2013

[11] S. Arsovski, Z. Arsovski, Z. Kalinic, I. Milanovic, D.R. Petrovic, and V. Rankovic, "Multi-objective supplier selection using genetic algorithm: a comparison between weighted sum and SPEA method" International Journal for Quality Research, Vol. 5, No. 4, pp.289-295, 2011,

[12] V. Rungreunganaun and C. Woarawichai, "Applying genetic algorithm for inventory lot sizing problem with supplier selection under storage space" World Academy of Science, Engineering and Technology, Vol. 74, No. 1, pp.303-308, 2013,

[13] M.K.A. Ariffin, N. Hakim, W. Khaksar, P.S. Pah, S. Sulaiman and S.H. Tang, "A hybrid method using analytic hierarchical process and artificial neural network for supplier selection" International Journal of Innovation, Management and Technology, Vol. 4, No. 1, pp.109-111, 2013 ,

[14] J. Kumar and N. Roy, "A hybrid method for vendor selection using neural network" International Journal of Computer Applications, Vol. 11, No. 12, pp.35-40, 2010

[15] C. Lakshmanpriya, C. Lavanpriya and N. Sangeetha, "Vendor selection in manufacturing industry using AHP and ANN" The SIJ Transactions on Industrial, Financial \& Business Management (IFBM), Vol. 1, No. 1, pp.29-34, 2013

[16] T.L. Saaty, "A scaling method for priorities in hierarchical structures" Journal of Mathematical Psychology, 15 (1), pp. 57-68, 1977 